\title{
FUTURE PHYSICIANS' PROFESSIONAL COMMUNICATION SKILLS TRAINING AT US UNIVERSITIES: STRUCTURE AND CONTENT
}

\begin{abstract}
Professional training of physicians able to apply their skills in order to reflect the patients' needs related to care, prevention and treatment of the diseases is one of the most common current trends in higher medical education. Due to the development of patient-centered relationships of physicians the attention of medical educators and scientists to the problem of professional communication and factors stimulating its development has grown drastically. The medical schools and colleges of US universities have already reached significant results in this area. Communicative training is one of the primary educational tasks of higher medical education in this country. Communicative courses are an obligatory component of professional training programs and curricula throughout all years of study. Valuable experience of the USA in this sphere may be useful for the educational development of our country. The paper analyzes the process of communicative training of future physicians at US universities; researches on the structure, content and evolution of professional communication programs and courses during the undergraduate years at medical schools and colleges. The key communicative skills have been defined and described. The main aspects of educational methodology referring to the evaluation of the communicative skills have been determined. The importance of physicians' professional communication and its influence on the treatment outcomes have been stated. Moreover, the paper discusses the difficulties of the professional communicative training implementation into the undergraduate university curriculum in the USA and describes the ways of solving the problematic aspects of professional communication training of medical students caused by the personal ethical and educational issues.

Key words: future physician, doctor-patient interaction, professional communication, communication skills training, US medical school, US university.

\section{INTRODUCTION}

The skills of interpersonal communication play an important role in the process of patient care and result in better treatment outcomes. The physician's ability to explain the necessity and importance of treatment procedure, demonstrate attention, understanding and compassion influences the biological and psychological health of a patient. Strong and kind relationships between the doctor and the patient result in the wish to follow the prevention, treatment and self-care recommendations [Ferguson, Candib, 2002; Kurtz, 2003; Mauksch, 2013). In addition, the communication of physicians with colleagues stipulate for the patient safety and improves the working atmosphere and job satisfaction. The underlined data emphasize the requirement of proper communicative strategies design and the methodology of the communicative skills development during the university years (Hausberg, 2012). The US medical schools and colleges are successful in this direction and their experience may be helpful to improve the process of forming and developing physicians' communication skills in Ukraine.
\end{abstract}




\section{THE AIM OF THE STUDY}

The aim of the study is to characterize the structure, content and the components of communicative training of future physicians; to determine and describe the key communicative skills and their development during the undergraduate years at the US medical schools.

\section{THEORETICAL FRAMEWORK AND RESEARCH METHODS}

The problem of future physicians' communicative skills forming has been analyzed at a number of international and world scientific conferences. The proceedings of these conferences as well as current scientific papers on professional communication of physicians (PCP) have formed a theoretic basement of our research. Up-to-date information concerning communicative training and doctor-patient communication has been retrieved from the official Web-sites of US universities and administrative organizations.

Different aspects of professional communication have been studied in the papers of Ukrainian (S. Kubitskyi, S. Poplavska, N. Semchenko) and foreign scientists. The communicative skills have been characterized by F. Duffy, I. Fentiman, I. Humenna, N. Kasevych, B. Korsch, G. Makoul, J. R. Tongue and others. The communicative competence of future physicians is the primary scientific objective in the papers of F. Duffy, R. Epstein, G. Flores， M. Hausberg， L. Krysak， N. Semchenko， B. Spietzberg. The communicative training in undergraduate years of medical schools has been researched by M. Champaneria, G. Flores, M. Kagava-Singer, C. Lum, J. Tongue.

The methodology of comparative pedagogy has been applied in the research. The systemic approach based on facts and followed by the principles of logical assumptions, links and objectiveness proves its validity.

\section{RESULTS}

The analysis of the scientific papers on the problem studied denotes that the professional communicative skills which reflect effective interpersonal relationships are formed by the combination of personal features, communicative and professional skills (Агаркова, 2010).

The improvement of interpersonal skills, cultivation of humanistic values and empathy (from Greek empatheia, literally "the capacity to place oneself in another's position") are the main objectives of undergraduate medical education in the USA (Association of American Medical Colleges, 2016). However, the spread of cynicism and the atrophy of idealism are considered to be a part of adaptation of future physicians for student and professional medical activities that consequently results in worsening their moral and ethical qualities. In order to correct the following situation medical educators have defined ten approaches to teaching expected to improve empathy during the study. They are development and improvement of interpersonal communication; analysis of audio- and video records of medical encounters; monitoring of the doctor-patient interaction; role plays; patient engagement; long-term observation of patients; hospitalization; study of literature and arts; visiting theatres; development of speaker's skills; group discussions of the procedure of medical encounters (Hojat, 2009). The development of interpersonal skills was determined as the main approach during the communication skills training (Hojat, 2009; Kurtz, 2003; Mauksch, 2013).

The communicative competence belongs to the six main competencies defined by the Accreditation Council for Graduate Medical Education (1999). The Association of American Medical Colleges (2016) has also published the recommendations for the communicative training. The following issues caused the necessity to develop and implement regulations on teaching, evaluation and assessment of communicative skills.

Nowadays, educators are facing the problems of defining the structure and content of required communicative skills and the development of a standardized evaluation model. 
Another pedagogical task is the integration of communicative and professional clinical development processes.

In order to solve this problem the communicative skills have been discussed at the meetings of the specialized faculties that agreed on the necessity of implementation of communication courses during the study time. Such courses were expected to be followed by clinical placements. It has been proved that the knowledge of proper communicative skills and strategies obtained during the first years at medical schools can be actively applied in further studies and improved, respectively (Haq, 2004).

One of the most important conferences of PCP was "The Conference of Professional Communication in Medicine" (1996) with a total of 200 participants from 21 countries all over the world. The key conclusions of the conference were later discussed at other seminars and published as the list of recommendations, namely, 1) communicative skills should be estimated; 2) clinical and communicative training should be balanced; 3) instructors should define and fulfill the patients' communicative needs; 4) communicative training should be professionally oriented; 5) teaching and estimation of the communication skills should be structured and grounded; 6) communicative skills should be estimated by monitoring students' communicative actions; 7) communicative teaching and evaluation programs should be analyzed and assessed; 8) departments should have all necessary resources and support (Association of American Medical Colleges, 2016).

The first stage of the communicative programs design was to define the content of communicative skills. The literature review has shown that fundamental communicative skills do not vary depending on the source of information (Kurtz, 2003; Mauksch, 2013). The most important sources of information on communicative skills are "Kalamazoo Consensus Statement", "Medical Schools Objectives Project Report III on Communication in Medicine" and other current methodical and scientific papers on medical education.

According to the "Kalamazoo Consensus Statement" stated in 1999 at the conference organized by the Institute of Communication and the Fetzer Institute (Makoul, 2001), the main components of the doctor-patient interaction are: 1) building the doctor-patient relationships; 2) beginning of the discussion; 3) collecting information; 4) listening to and understanding the patient; 5) transfer of information; 6) finding the compromise; 7) ending the discussion. The list of Kalamazoo Consensus Statement communicative competences formed the basis for the further study of physicians' communicative skills. As a result, several investigations were performed in the next decade aimed at developing and assessing these skills.

In 2001, the scientists at Harvard medical school carried out the research with the aim of implementing the unique plan of communicative skills assessment and training. The educators proposed a combination of theoretical and practical learning in the first years of study. As a result, the institution launched the program of communicative training during all four years at medical schools (Rider, 2006). Thus, the US scientists have made the first steps in the process of implementing physicians' communication training into the undergraduate medical schools' curriculum.

The communication skills training during clinical placements was introduced in 2001-2002 by the three US higher education institutions, namely, New York University, the University of Massachusetts and Case Western Reserve University. The electives designed for the third and fourth years were highly assessed by both instructors and students. The latter obtained the skills of planning medical encounters and improved communication skills (Mauksch, 2013). The methodology of the courses included the skills demonstration and assessment by mentors, placement supervisors, personal feedback and standard patients (SP), i.e. individuals trained to act as real patients to simulate a set of 
symptoms or problems. The basic communication skills were divided into five sections of medical encounters and referred to 1) determining the reason of visit; 2) identification and understanding the patient's intention; 3) presenting information and recommendations; 4) discussion and agreement of the treatment plan; 5) mutual and agreed ending of the encounter.

The applied approach to the encounter components statement resembles the CalgaryCambridge model of medical encounter based on the structural and communicative components of personal interaction. The abovementioned model consists of five consequent stages: 1) the beginning of the encounter (preparation, stating the reason of the visit); 2) data collection; 3) physical examination; 4) explanation of the diagnosis and treatment plan; 5) ending of the encounter (regulated ending, planning of the next visit) (Kurtz, 2003). Such staging of the encounter is common in professional medical communication teaching as it has a clear and well-defined structure that corresponds with the usual arrangement of medical history and includes necessary communication skills defined by the "Kalamazoo Consensus Statement" (Makoul, 2001).

Both communicative strategies and rules can be learnt and taught, however they require practical training (Mauksch, 2013). Therefore, the professional communication is trained during the years of clinical placements. After specific short-term training courses placement supervisors can teach communication skills to students through the demonstration of proper communicative behavior in severe cases.

Since 2015-2016 higher medical institutions of the USA changed the approach to the curriculum design (NYU School of Medicine, 2016; Ohio State University College of Medicine, 2016; University of Illinois College of Medicine, 2016). From the first day at university students can interact in professional environment and develop communication skills. Thus, the theoretic and practical communication skills training of future physicians covers two pre-clinical and two clinical years of study (Figure 1).

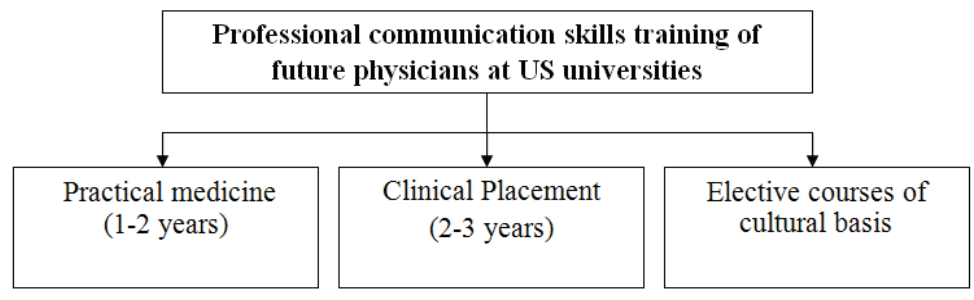

Fig. 1. Structure of Future Physicians' Communicative Skills Training at US Universities

During the pre-clinical stage the communicative principles are the components of the course "Practical medicine" which covers the first two years of study (Ohio State University College of Medicine, 2016; University of Illinois College of Medicine, 2016). During the clinical placements medical students practice the skills of professional communication. At this stage communication is one of the primary training objectives.

In addition, during the first year of study students are offered a wide range of elective courses including humanities, oriented at the development of cultural and linguistic components of professional communication. They can choose from four to six elective courses that include such subjects as "Medicine and Arts", "International Health Care", "Medical Spanish", "Basics of Religion”, etc. (Yele School of Medicine, 2016). 
While the personal features and ethical behavior play a dominant role in doctorpatient interaction, the role of linguistic competence is crucial, too. It is well-known that a vast majority of US population is formed by the foreign population and ethnical groups. This category of patients are not usually fluent in English or do not speak English at all (Ferguson, 2002). However, foreign languages are not considered as a criterion of professional training. Foreign languages are the constituent parts of general cultural competences. Foreign languages courses are elective (Yele School of Medicine, 2016).

\section{CONCLUSIONS}

Thus, the results of the research performed prove the following:

1. The process of future physicians' communication skills training in the USA is more concentrated on the ethical aspects of practical PCP with patients. Linguistic competences are the components of cultural ones which influence the development of physicians' communicative competence; however, they are not the primary aspects of PCP during the undergraduate years.

2. The development of interpersonal communicative skills is the part of a) "Practical medicine" course during the first and second years, b) the period of clinical placement in the second-third or third-forth years at medical school or colleges and c) elective courses designed to develop cultural and linguistic communicative aspect.

3. Teaching of PCP is based on the list of determined communication skills with the help of standard teaching methods in higher medical education institutions.

The future directions of the research are the investigation of using new educational tools, computer and information technologies in the process of PCP training at US universities and the communication skills assessment system.

\section{REFERENCES}

1. Accreditation Council for Graduate Medical Education and American Board of Medical Specialties. (1999). General Competencies: Minimal Program Requirement Language. Retrieved 12.09.2016 from : http://www.acgme.org.

2. Association of American Medical Colleges. (2016). Medical School Objectives Project. Retrieved 30.08.2016 from : http:/www.aamc.org/meded/msop.

3. Ferguson, W., Candib, L. (2002). Culture, Language and the Doctor-Patient Relationship. Family Medicine, Volume 34, Issue 5, pp. 352-361. Retrieved 20.09.2016 from : http://escholarship.umassmed.edu/.

4. Haq, C., Steele, D., Marchand, L., Seibert, C., Brody, D. (2004). Integrating the Art and Science of Medical Practice: Innovations in Teaching Medical Communication Skills. Family Medicine, Volume 36, January Supplement, pp. 43-49.

5. Hausberg, M., Hergert, A., Kröger, C., Bullinger, M., Rose, M., Sylke, A. (2012). Enhancing Medical Students' Communication Skills: Development and Evaluation of an Undergraduate Training Program. Retrieved 26.08.2016 from : http://bmcmededuc. Biomedcentral.com/articles/10.1186/1472-6920-12-16.

6. Hojat, M. (2009). Ten Approaches for Enhancing Empathy in Health and Human Services Culture. Journal of Health and Human Services Administration, No 31, pp. 412-450.

7. Kurtz, S., Silverman, J., Benson, J., Draper, J. (2003). Content and Process in Clinical Method Teaching: Enhancing the Calgary-Cambridge Guides. Academic Medicine: Journal of the Association of American Medical Colleges, Volume 78, Issue 8, pp. 802-809.

8. Makoul, G. (2001). Essential Elements of Communication in Medical Encounters: the Kalamazoo Consensus Statement. Academic Medicine: Journal of the Association of American Medical Colleges, Volume 76, Issue 4, pp. 390-393. 
9. Mauksch, L, Farber, S, Greer, H. (2013). Design, Dissemination, and Evaluation of an Advanced Communication Elective at Seven U.S. Medical Schools. Academic Medicine: Journal of the Association of American Medical Colleges, Volume 88, Issue 6, pp. 843-851.

10. NYU School of Medicine. (2016). Education and Training. Retrieved 10.09.2016 from : http://www.med.nyu.edu/school/education-training.

11. Rider, E. A., Hinrichs, M. M., Lown, B.A. (2006). A Model for Communication Skills Assessment across the Undergraduate Curriculum. Medical Teacher, Volume 28, Issue 5, pp. 127-134.

12. The Ohio State University. College of Medicine. (2016). The LSI Curriculum. Retrieved 13.09.2016 from : http://medicine.osu.edu/students/lsi_curriculum/pages/index.aspx.

13. University of Illinois. College of Medicine. (2016). College-Wide Retreat Accelerates Plans for Curriculum Renewal; Accrediting Body Approves Plans for M1 Expansion to Peoria and Rockford. Retrieved 25.09.2016 from : http://medicine.uic.edu/cms/One.aspx? portalId $=443021$ \&pageId $=32089924$.

14. Yale School of Medicine. (2016). Medical Education at Yale. Retrieved 21.09.2016 from : http://medicine.yale.edu/education/rebuild/secondLook16Apr15_217799_1095_5.pdf.

15. Агаркова, А. О. (2010). Деякі аспекти формування професійно-етичної культури лікаря [Some Aspects of Physicians' Professional and Ethical Culture Development]. Вісник Луганського національного університету імені Тараса Шевченка. Педагогіка [The Bulletin of Taras Shevchenko Luhansk National University. Pedagogy], No 7 (194), pp. 10-14 (in Ukrainian). 